Check for updates

Cite this: Nanoscale Adv., 2019, 1, 4665

Accepted 17th October 2019

DOI: 10.1039/c9na00645a

rsc.li/nanoscale-advances

\section{Borohydride stabilized gold-silver bimetallic nanocatalysts for highly efficient 4-nitrophenol reduction $\uparrow$}

\author{
Nathaniel E. Larm, (D) $\$$ Jason A. Thon, $\$$ Yahor Vazmitsel, Jerry L. Atwood (D) \\ and Gary A. Baker (iD*
}

Bimetallic $\mathrm{Au}_{x} \mathrm{Ag}_{1-x}$ nanoparticles, prepared using sodium borohydride as the sole reducing and capping agent for various $\mathrm{NaBH}_{4}$ : metal molar ratios, were investigated as catalysts for 4-nitrophenol reduction. This approach yielded the highest catalytic activities observed for this model reaction to date.

Noble metal nanoparticles (NPs) are promising catalysts for a variety of organic reactions such as 4-nitroarene reduction using sodium borohydride, ${ }^{1-5}$ aerobic oxidation of alkyl benzenes to benzaldehydes, ${ }^{6-8}$ and alkylation of primary amines to secondary amines in the presence of an alcohol..$^{9-11}$ It is well known that the catalytic potential of noble metal NPs relies heavily on their size, shape, crystallinity, dispersity, and surface chemistry. ${ }^{9,12}$ In this regard, strong stabilizing ligands typically hinder catalytic activity by creating a diffusion barrier between reactants and the NP surface, with tightly-bound surfactants leading to slower transport of reactants and poor catalytic activity. ${ }^{13}$ This flaw was turned into a feature by Astruc and co-workers in 2014 when they reported the synthesis of gold nanoparticles (AuNPs) stabilized by $\mathrm{NaBH}_{4}$ for the catalytic reduction of 4-nitrophenol (4-NP) to 4-aminophenol (4-AP) in the presence of $\mathrm{NaBH}_{4},{ }^{14}$ providing an intriguing circumstance where $\mathrm{BH}_{4}{ }^{-}$participated in the catalytic system as both the catalyst surfactant and as one of the reactants. Their catalyst preparation used clever manipulation of the concentration of $\mathrm{NaBH}_{4}$, a common reducing agent ${ }^{15}$ but seldom-utilized stabilizing ligand, to produce AuNPs possessing the highest activity for this reaction yet reported.

Bimetallic NPs provide an interesting opportunity to expand the current catalog of nanocatalysts. In particular, bimetallic gold/silver nanoparticles (AuAgNPs) provide an inexpensive alternative to monometallic AuNP catalysts while generally

Department of Chemistry, University of Missouri, Columbia, MO, 65211, USA. E-mail: bakergar@missouri.edu

† Electronic supplementary information (ESI) available: Experimental details, images of samples, additional spectra, and TEM images. See DOI: 10.1039/c9na00645a

\$ These authors contributed equally to this work. possessing higher catalytic activity for the reduction of nitroarenes. ${ }^{16-22}$ Herein, we investigate a slightly modified Astruc method for the synthesis of monometallic AuNPs and AgNPs as well as bimetallic $\mathrm{Au}_{x} \mathrm{Ag}_{1-x} \mathrm{NPs}$ (where $x$ ranges from 0.9 to 0.1 in 0.1 increments) using $\mathrm{NaBH}_{4}$ as the sole reducing/stabilizing agent. Three distinct molar ratios of reducing agent to metal (denoted herein as $R$ values; specifically, $R=2,5$, and 10) were used to create sets of monometallic/bimetallic NP solutions as shown in Tables S1-S3.† These colloidal NP solutions were then used as catalysts in the reduction of 4-NP to 4-AP in the presence of excess $\mathrm{NaBH}_{4}$, which resulted in the highest observed catalytic activity for this reaction when using noble metal NPs in water at room temperature.

The $\mathrm{Au}_{x} \mathrm{Ag}_{1-x} \mathrm{NP}$ colloids were initially screened using UV-vis spectrophotometry (Fig. 1 and S1-S11†), monitoring for changes in their localized surface plasmon resonance (LSPR) bands over time as an indication of colloid evolution and stability.

The LSPR bands of the as-synthesized monometallic solutions indicate the formation of very small AuNPs $\left(\mathrm{LSPR}_{\max }\right.$ of $\sim 510 \mathrm{~nm}$ ) and somewhat larger AgNPs $\left(\mathrm{LSPR}_{\max }\right.$ of $\left.\sim 410 \mathrm{~nm}\right)$ in the $x=1.0$ and 0.0 solutions, respectively, while the bimetallic solutions possess intermediate LSPR bands. Within $5 \mathrm{~d}$ of synthesis, aggregation in the form of a black precipitate was observed in the $R=5$ AgNPs as well as all samples containing more than $50 \mathrm{~mol} \% \mathrm{Ag}(x<0.5)$ from the $R=10$ sample set. After aging for $20 \mathrm{~d}$, the AgNP solutions from the $R=2,5$, and 10 sample sets, bimetallic $\mathrm{Au}_{0.1} \mathrm{Ag}_{0.9}$ NPs from the $R=5$ sample set, and bimetallic $\mathrm{Au}_{x} \mathrm{Ag}_{1-x} \mathrm{NPs}$ (for $x=0.1,0.2,0.3,0.4$ ) from the $R=10$ sample set also possessed such aggregates. This aggregation is attributed to a decrease in surface potential imparted by electron injection into the $\mathrm{NP}$ by $\mathrm{BH}_{4}{ }^{-}$, resulting in destabilization of the colloidal dispersion. ${ }^{3}$ All other samples showed colloidal stability throughout $30 \mathrm{~d}$, with some broadening and red-shifting of the LSPR band evident in some cases. Bubbles were also observed in these aged solutions, indicative of $\mathrm{H}_{2}$ gas production from the hydrolysis of the borohydride to borohydroxides of the form $\left[\mathrm{BH}_{y}(\mathrm{OH})_{4-y}\right]^{-}$. 


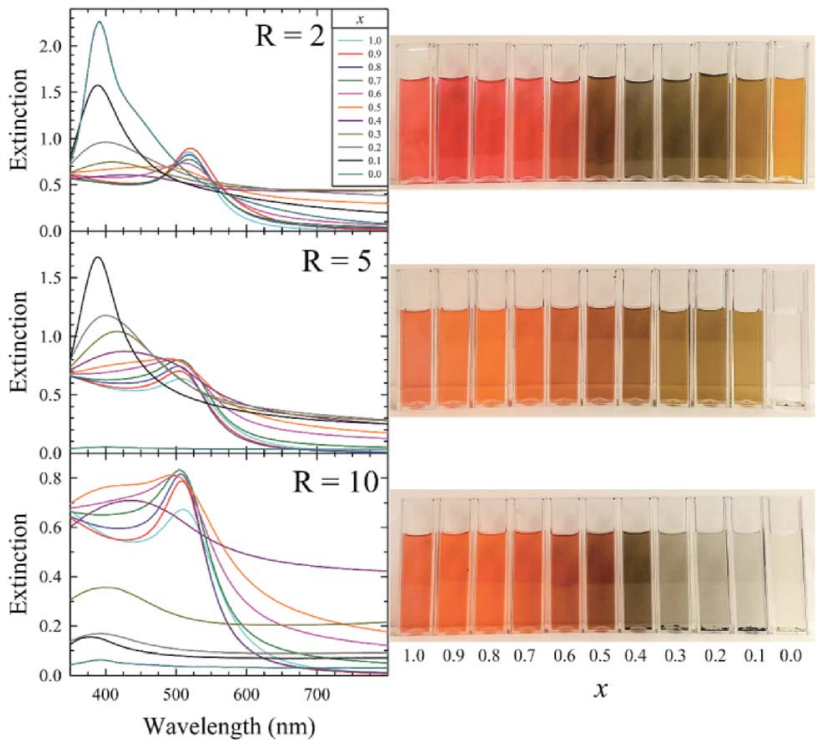

Fig. 1 UV-vis spectra of borohydride-capped $\mathrm{Au}_{x} \mathrm{Ag}_{1-x} \mathrm{NPs}$ alongside images of the samples aged for $5 \mathrm{~d}$. The $R$ values provided in the left panels denote the number of equivalents of $\mathrm{NaBH}_{4}$ per metal atom employed in the synthesis. Colloidal instability in the form of black precipitates affiliated with sample decolouration is observed for very low $x$ values (high silver content) in the $R=5(x=0.0)$ and $R=10(x \leq$ 0.4) sample sets.

A comparison of the UV-vis spectrum of an equivolume mixture of AuNPs and AgNPs with that of our bimetallic $\mathrm{Au}_{0.5^{-}}$ $\mathrm{Ag}_{0.5} \mathrm{NPs}$ is shown in Fig. S12. $\dagger$ The latter sample exhibits peak broadening and a decrease in peak intensity when compared to the spectra from the monometallic samples, consistent with the formation of intermetallic particles. Further, energy-dispersive X-ray spectroscopy (EDS) spot analysis was used to interrogate the atomic composition of our bimetallic $R=5 \mathrm{Au}_{0.5} \mathrm{Ag}_{0.5} \mathrm{NPs}$. The proportions of $\mathrm{Au}$ and $\mathrm{Ag}$ were determined to be 36.7 and 63.3 atom\%, respectively, as calculated from the EDS spectrum (Fig. S13†). We attribute the discrepancy between the asprepared $(50: 50)$ and as-measured $(37: 63)$ atomic ratios to low X-ray counts and the high relative error of the EDS measurement ( $\sim 30 \%)$, a consequence of the small NP size. We propose that these bimetallic NPs comprise a pseudo-random composition that is primarily governed by the relative concentrations of available metal atoms in solution, although the small NP sizes thwarted our attempts to elucidate the exact atomic composition via EDS mapping.

Transmission electron microscopy (TEM) images were acquired for the following $\mathrm{Au}_{x} \mathrm{Ag}_{1-x} \mathrm{NPs}$ samples after aging for 5 d: $R=2$ for $x=0.6,0.3,0.0$ (Fig. 2); $R=5$ for $x=1.0,0.3$ (Fig. S14†); and $R=10$ for $x=0.7,0.5$ (Fig. S15†). These representative images and respective histograms indicate narrow size distributions and mostly sub-10 nm particle sizes for all but the $R$ $=2$ AgNPs, an anomaly which we are tentatively attributing to the instability of borohydride-capped AgNPs, as the solutions of AgNPs when $R=5$ or 10 contained black precipitate at this time point. Further, the TEM images suggest the formation of metal networks either in solution or upon drying on the grid, making NP size assessment difficult (at least $300 \mathrm{NP}$ were counted, with
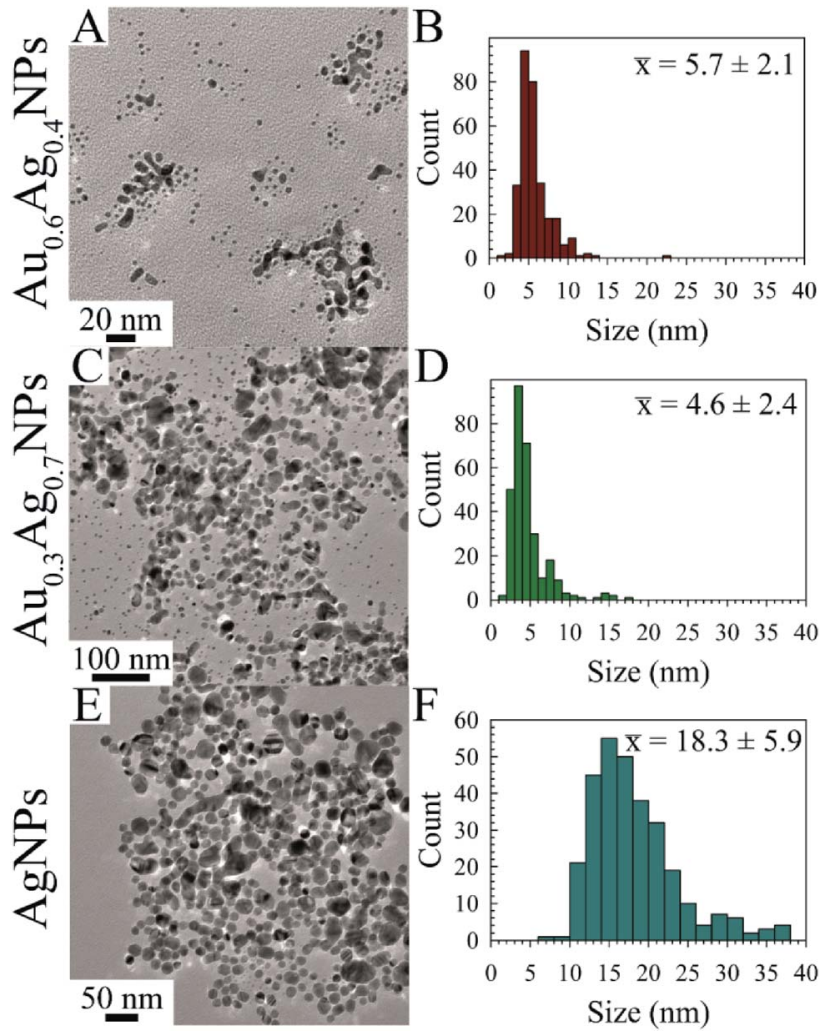

Fig. 2 TEM images and related size histograms for borohydridecapped $\mathrm{Au}_{x} \mathrm{Ag}_{1-x} \mathrm{NPs}$ for $(\mathrm{A}$ and $\mathrm{B}) x=0.6$; $(\mathrm{C}$ and $\mathrm{D}) \mathrm{x}=0.3$; and $(\mathrm{E}$ and F) $x=0.0$ (i.e., AgNPs). The borohydride-to-metal molar ratio ( $R$ value) is 2 for these samples.

some level of inaccuracy as the branching metal networks were ignored). Notably, these networks were also observed by Astruc et al. ${ }^{14}$ The smallest observed NPs were associated with the $R=2$ $\mathrm{Au}_{0.3} \mathrm{Ag}_{0.7} \mathrm{NP}$ solution, with an average particle size of $4.6 \pm$ $2.4 \mathrm{~nm}$.

The catalytic activity of $5 \mathrm{~d}$-old $\mathrm{Au}_{x} \mathrm{Ag}_{1-x} \mathrm{NPs}$ was measured through the model reduction of 4-nitrophenol (4-NP) to 4aminophenol (4-AP) in the presence of a large excess ( $>200-$ fold) of sodium borohydride $\left(\mathrm{NaBH}_{4}\right)$, with experimental details provided in the ESI. Briefly, $2.1 \mathrm{~mL}$ of aqueous $0.2 \mathrm{mM}$ 4- $\mathrm{NP}$ and $0.9 \mathrm{~mL}$ of aqueous $0.1 \mathrm{M} \mathrm{NaBH}_{4}$ was added to a poly(methyl methacrylate) (PMMA) cuvette, resulting in a yellow solution of 4-nitrophenolate $\left(\lambda_{\max }=400 \mathrm{~nm}\right)$. To this solution, $34 \mu \mathrm{L}$ of aqueous $0.25 \mathrm{mM}$ metal catalyst solution (that is, $[\mathrm{Au}]+[\mathrm{Ag}]=0.25 \mathrm{mM}$ ) was added (a catalyst loading of $2.0 \mathrm{~mol} \%$ metal to 4 -NP was kept constant throughout), and the cuvette was capped, inverted to mix, and placed in the UVvis spectrometer to begin measuring solution absorbance at $400 \mathrm{~nm}$, similar to techniques used in previous publications. ${ }^{23}$ It should be noted that samples containing black precipitate were not assessed for catalytic performance due to inaccuracies in calculating the remaining metal concentration. In the presence of excess $\mathrm{NaBH}_{4}$, the reaction proceeds via pseudofirst-order kinetics and a linear relationship between $\ln \left(A_{0} /\right.$ $A_{t}$ ) versus time is observed, the slope of which equals the 
catalytic rate $\left(k_{\mathrm{app}}\right)$. These plots and the resulting $k_{\text {app }}$ values are summarized in Fig. 3.

While it is common during 4-NP reduction to observe an initial induction period wherein dissolved oxygen back-reacts with $4-\mathrm{AP},{ }^{24}$ such a delay is only observed during the slower reactions when using AuNPs and AgNPs. We propose that the faster kinetics imparted by our bimetallic NPs greatly shorten this induction period, limiting it to the time required to invert our cuvette for mixing. The reactions were considered complete when the decrease in absorbance at $400 \mathrm{~nm}$ slowed substantially (corresponding to a $\ln \left(A_{0} / A_{t}\right)$ value of 3 , equivalent to $95 \%$ reaction completion), and were terminated after $5 \mathrm{~min}$ had passed. Generally, bimetallic $\mathrm{Au}_{x} \mathrm{Ag}_{1-x} \mathrm{NPs}$ with medium-tohigh silver contents (i.e., $x \leq 0.7$ ) demonstrated higher catalytic rates within a given $R$ value sample set.

Turnover frequency (TOF) should be preferred over $k_{\text {app }}$ when reporting comparative catalytic activity of NPs due to the former's incorporation of the molar ratio of catalyst to substrate. More specifically, this value is calculated by dividing the moles of substrate (in this case, $n_{4-\mathrm{NP}}$ ) by the product of moles of catalyst $\left(n_{\mathrm{m}}\right)$ and the reaction time $\left(t_{\mathrm{rxn}}\right)$ in hours, then correcting for reaction completion, as per eqn (1).

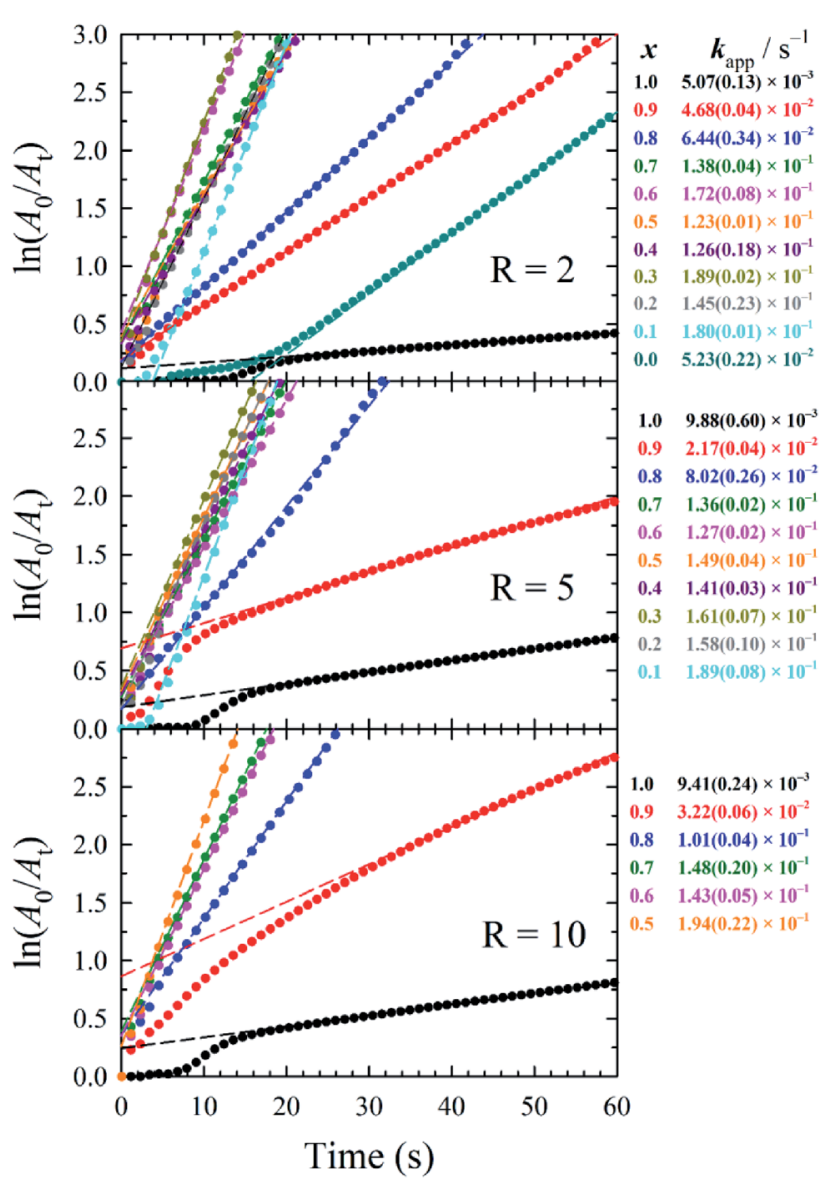

Fig. 3 Plots depicting the pseudo-first-order kinetics of 4-NP reduction and associated catalytic rates $\left(k_{\text {app }}\right)$ using $5 \mathrm{~d}$-old borohydride-stabilized $\mathrm{Au}_{x} \mathrm{Ag}_{1-x} \mathrm{NP}$ nanocatalysts $(R=2,5$, and 10, top to bottom). Excluded $x$ values for a particular $R$ value indicate the observation of appreciable colloidal precipitation after aging for $5 \mathrm{~d}$.

$$
\mathrm{TOF}=\frac{n_{4-\mathrm{NP}}}{\left(n_{\mathrm{m}}\right)\left(t_{\mathrm{rxn}}\right)} \times \frac{\text { completion } \%}{100}
$$

Herein, we used $2.0 \mathrm{~mol} \%$ metal to $4-\mathrm{NP}$ and define the reaction time as the time to attain $\ln \left(A_{0} / A_{t}\right)=3(95 \%$ reaction completion). This reaction completion $\%$ has the benefit of incorporating most of the reaction progress while simultaneously negating instrument sensitivity concerns arising when the residual 4-nitrophenolate concentration becomes very small. Under these parameters, $\mathrm{Au}_{0.3} \mathrm{Ag}_{0.7} \mathrm{NPs}$ from the $R=2$ sample set demonstrated the highest catalytic activity, with a calculated TOF of $12160 \mathrm{~h}^{-1}$ (Fig. 4A and Table S4 $\dagger$ ). Notably, several of our bimetallic NPs at each $R$ value outperformed the record previously claimed for this reaction using a AuNP catalyst $(\mathrm{TOF}=9000$ $\left.\mathrm{h}^{-1}\right),{ }^{14}$ despite our use of more stringent reaction completion conditions (e.g., the above reference reported a completion time corresponding to a $\ln \left(A_{0} / A_{t}\right)=2$, or $86 \%$ completion, and did not correct for this in their calculation of TOF). To the best of our knowledge, these $\mathrm{Au}_{x} \mathrm{Ag}_{1-x} \mathrm{NPs}$ possess the highest catalytic activities for this specific catalytic reaction yet reported. The proposed reason for such a pronounced increase in TOF when using bimetallic NPs is two-fold: first, a size regulating effect is evident for solutions of mixed metals, resulting in populations of smaller NPs and a potential increase in the number of surface atoms available for catalysis. Second, the presence of guest metals

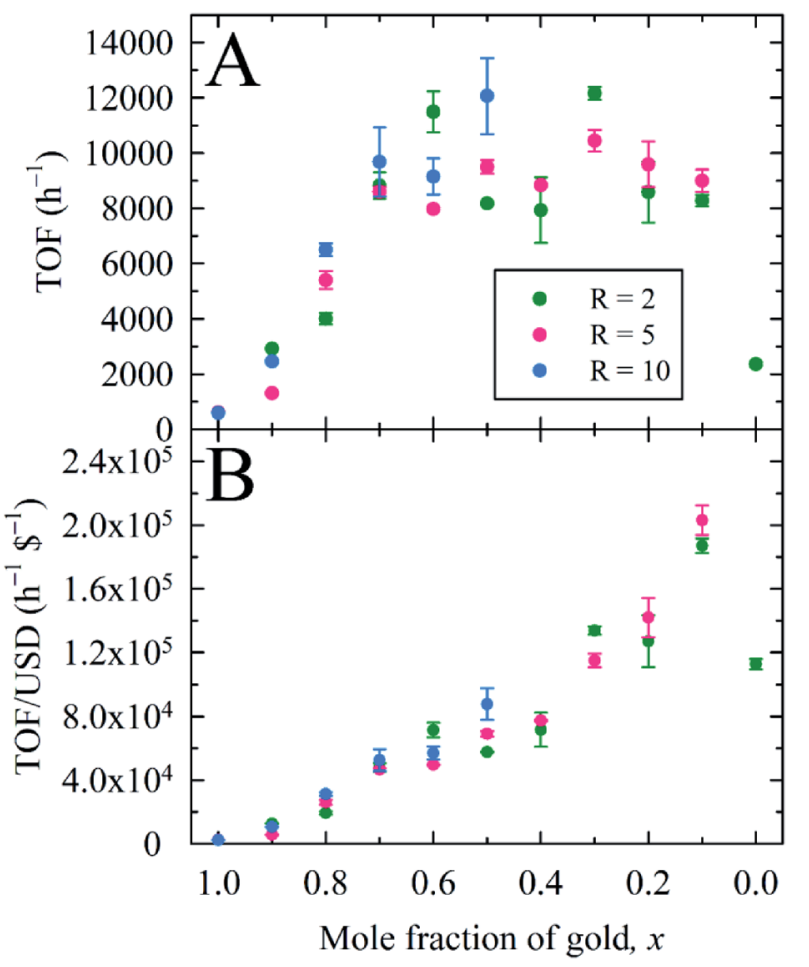

Fig. 4 (A) Turnover frequency (TOF) and (B) TOF per U.S. dollar (USD), expressed as functions of the overall nanoparticle composition, for borohydride-stabilized $\mathrm{Au}_{x} \mathrm{Ag}_{1-x} \mathrm{NPs}$ applied as nanocatalysts for 4-NP reduction. Panel (B) illustrates the economic viability of replacing $A u$ with $\mathrm{Ag}$ in this catalytic system by way of a monotonic increase in the TOF per USD. Economic performance is based on current representative vendor prices for the metal precursors used (see ESI + ). 
within an ordered crystalline structure results in disharmonious, defect-laden surfaces, increasing the number of active sites for catalytic activity and surface rearrangement of stabilizing ligands. Further study is required to fully understand and quantify the amount of catalytic enhancement imparted, in general, when incorporating bimetallic systems.

A recyclability assessment was performed using $\mathrm{Au}_{0.3} \mathrm{Ag}_{0.7} \mathrm{NPs}$ for $R=2$ (Table S5 and Fig. S16†). The initial catalytic cycle was performed as specified above, and, once the reaction was complete, the cuvette was spiked with $84 \mu \mathrm{L}$ of $5.0 \mathrm{mM} 4-\mathrm{NP}$ and $90 \mu \mathrm{L}$ of $0.1 \mathrm{M} \mathrm{NaBH}_{4}$ to restart the reaction. This recycling procedure was performed five sequential times using the same cuvette and catalytic solution. Unfortunately, we find that the TOF experiences an exponential decay in each sequential cycle, dropping from an initial value of $12260 \mathrm{~h}^{-1}$ to $1570 \mathrm{~h}^{-1}$ after six cycles. This is, however, not surprising as the high surface energy of nanoscale colloids invariably results in instability, aggregation, and eventual loss of catalytic activity. Indeed, in practice nanocatalysts are typically protected against colloidal aggregation and oxidation by coating with a suitable polymer (e.g., poly $(N$-vinyl-2pyrrolidone) PVP), deposition on a solid inorganic support, or encapsulation within a porous scaffold to yield superior stability, durability, and recoverability relative to the free nanocatalyst. ${ }^{25-27}$ Nonetheless, the final TOF observed after six catalytic cycles for our unsupported catalysts remains high compared to typical nitroarene reduction nanocatalysts reported in the literature. ${ }^{14}$

As a metric to compare the price and activity of our bimetallic NPs, we prepared a plot of TOF per USD $\left(\mathrm{h}^{-1} \mathrm{~S}^{-1}\right)$ versus the $x$ value for $\mathrm{Au}_{x} \mathrm{Ag}_{1-x} \mathrm{NPs}$ (Fig. 4B). Our aim is to show that not only are these bimetallic NPs the best catalysts for this system yet reported, but they are much more cost effective than the pure, monometallic AuNPs typically utilized. Indeed, higher $\mathrm{Ag}$ concentrations (lower $x$ values) yielded higher activities per $\$$; especially noteworthy is the very high activity coupled with reduced cost for the $\mathrm{Au}_{0.1} \mathrm{Ag}_{0.9} \mathrm{NP}$ sets.

In summary, we report a method for synthesizing bimetallic $\mathrm{Au}_{x} \mathrm{Ag}_{1-x} \mathrm{NPs}$ capped with $\mathrm{NaBH}_{4}$ which possess higher catalytic activity for the reduction of 4-NP to 4-AP than their corresponding monometallic counterparts when utilizing the same total amount of metal. Displaying TOF values up to $12160 \mathrm{~h}^{-1}$, to the best of our knowledge, these nanoparticles offer the fastest nanocatalytic rates yet observed for nitroarene reduction in water under ambient conditions. Finally, this research suggests wider consideration for the financial and functional benefits of employing silver as a substitute for (or complement to) gold within nanocatalytic systems.

\section{Conflicts of interest}

There are no conflicts to declare.

\section{Notes and references}

1 S. Zhao, A. Das, H. Zhang, R. Jin, Y. Song and R. Jin, Pro. Nat. Sci.-Mater., 2016, 26, 483-486.

2 G. Li and R. Jin, Acc. Chem. Res., 2013, 46, 1749-1758.
3 R. Ciganda, N. Li, C. Deraedt, S. Gatard, P. Zhao, L. Salmon, R. Hernández, J. Ruiz and D. Astruc, Chem. Commun., 2014, 50, 10126-10129.

4 Y. S. Seo, E.-Y. Ahn, J. Park, T. Y. Kim, J. E. Hong, K. Kim, Y. Park and Y. Park, Nanoscale Res. Lett., 2017, $12,7$.

5 T. Aditya, A. Pal and T. Pal, Chem. Commun., 2015, 51, 94109431.

6 A. V. Biradar and T. Asefa, Appl. Catal., A, 2012, 435-436, 1926.

7 A. S. K. Hashmi and G. J. Hutchings, Angew. Chem., Int. Ed., 2006, 45, 7896-7936.

8 B. Guan, D. Xing, G. Cai, X. Wan, N. Yu, Z. Fang, L. Yang and Z. Shi, J. Am. Chem. Soc., 2005, 127, 18004-18005.

9 H. Lin, L. Xia-Bing, N. Ji, L. Yong-Mei, C. Yong, H. He-Yong and F. Kang-Nian, Chem.-Eur. J., 2010, 16, 13965-13969.

10 O. Saidi, A. J. Blacker, G. W. Lamb, S. P. Marsden, J. E. Taylor and J. M. J. Williams, Org. Process Res. Dev., 2010, 14, 10461049.

11 K. Shimizu, M. Nishimura and A. Satsuma, ChemCatChem, 2009, 1, 497-503.

12 J. T. L. Gamler, H. M. Ashberry, S. E. Skrabalak and K. M. Koczkur, Adv. Mater., 2018, 30, 1801563.

13 S. Campisi, M. Schiavoni, C. Chan-Thaw and A. Villa, Catalysts, 2016, 6, 185.

14 C. Deraedt, L. Salmon, S. Gatard, R. Ciganda, R. Hernandez, J. Ruiz and D. Astruc, Chem. Commun., 2014, 50, 1419414196.

15 M. Dasog, W. Hou and R. W. J. Scott, Chem. Commun., 2011, 47, 8569-8571.

16 R. Ferrando, J. Jellinek and R. L. Johnston, Chem. Rev., 2008, 108, 845-910.

17 S. Ravula, J. B. Essner, W. A. La, L. Polo-Parada, R. Kargupta, G. J. Hull, S. Sengupta and G. A. Baker, Nanoscale, 2015, 7, 86-91.

18 E. W. Harak, K. M. Koczkur, D. W. Harak, P. Patton and S. E. Skrabalak, ChemNanoMat, 2017, 3, 815-821.

19 S. E. Skrabalak, J. Chen, S. Neretina and D. Qin, Part. Part. Syst. Charact., 2018, 35, 1800111.

20 J. B. Essner, C. H. Laber and G. A. Baker, J. Mater. Chem. A, 2015, 3, 16354-16360.

21 X. Wang, S. Chen, G. Reggiano, S. Thota, Y. Wang, P. Kerns, S. L. Suib and J. Zhao, Chem. Commun., 2019, 55, 1249-1252.

22 N. E. Larm, D. Madugula, M. W. Lee and G. A. Baker, Chem. Commun., 2019, 55, 7990-7993.

23 N. E. Larm, J. B. Essner, K. Pokpas, J. A. Canon, N. Jahed, E. I. Iwuoha and G. A. Baker, J. Phys. Chem. C, 2018, 122, 5105-5118.

24 E. Menumerov, R. A. Hughes and S. Neretina, Nano Lett., 2016, 16, 7791-7797.

25 K. Zhang, J. M. Suh, J.-W. Choi, H. W. Jang, M. Shokouhimehr and R. S. Varma, ACS Omega, 2019, 4, 483-495.

26 H. Hu, J. H. Xin, H. Hu, X. Wang, D. Miao and Y. Liu, J. Mater. Chem. A, 2015, 3, 11157-11182.

27 D. Wang and D. Astruc, Chem. Soc. Rev., 2017, 46, 816-854. 